Informatio: Journal of Library and Information Science Vol. 1(1), 99-120, Januari 2021

ISSN 2775-0043 (Online)

\title{
Identifikasi dan penyimpanan koleksi Museum Zoologi Sekolah Ilmu dan Teknologi Hayati (SITH) Institut Teknologi Bandung Jatinangor
}

\author{
Jaenal Ihsan Kaenuwihanulaha*, Ninis Agustini Damayani ${ }^{\mathrm{b}}$, Rully Khairul Anwar ${ }^{\mathrm{c}}$ \\ aPT. Alif Samudra Benua Bandung \\ bcFakultas Ilmu Komunikasi Universitas Padjadjaran Bandung
}

\begin{abstract}
Abstrak
Museum berperan sebagai sarana pendidikan dan penelitian bagi pengunjung. Salah satunya adalah Museum Zoologi SITH ITB yang memiliki koleksi spesimen awetan basah dan kering. Spesimen awetan menjadi koleksi museum yang rentan rapuh dan rusak. Museum membantu melestarikan hewan ke bentuk spesimen agar dapat dilihat oleh pengunjung. Penelitian ini bertujuan untuk mengetahui identifikasi dan penyimpanan koleksi Museum Zoologi SITH ITB. Metode penelitian yang digunakan kualitatif melalui pendekatan studi kasus. Adapun subjek penelitian ialah kepala museum, kurator, dan pengunjung museum. Teknik pengumpulan data dilakukan melalui wawancara mendalam, observasi, dan tinjauan literatur. Sesuai hasil penelitian, koleksi museum ditentukan berdasarkan kebijakan pemilihan jenis satwa yang akan dijadikan spesimen, cara pengawetan dan penyimpanan (display), dan informasi taksonomi. Jenis satwa yang dipilih ialah yang memiliki tulang belakang dan tidak memiliki tulang belakang, di antaranya invertebrata, ikan, amfibi, reptil, burung, dan mamalia melalui awetan basah dan kering. Penyimpanan koleksi Museum Zoologi SITH ITB dilakukan melalui proses analisis koleksi, pengawetan, pelabelan, dan penyimpanan. Pertama, kurator dalam melakukan proses analisis koleksi mengamati hewan yang akan dimatikan untuk dijadikan spesimen dan membuat surat perizinan kepada lembaga berwenang. Kedua, kurator dalam melakukan pengawetan melakukan pengawetan koleksi spesimen basah dan kering disesuaikan dengan spesimennya sendiri. Ketiga, kurator dalam kegiatan pelabelan melabeli koleksi spesimen basah dan kering sesuai penempatan wadah. Ketiga, kurator dalam kegiatan penyimpanan menyimpan koleksi awetan basah dan kering secara berbeda. Penelitian mengenai identifikasi koleksi dan penyimpanan koleksi di Museum Zoologi SITH ITB dapat membantu kurator dalam mengenalkan awetan spesimen kepada pengunjung. Simpulan penelitian adalah bahwa kurator Museum Zoologi SITH ITB berperan penting dalam merawat koleksi dan memperkenalkan koleksi museum pada pengunjung. Hal ini menjadikan koleksi Museum Zoologi SITH ITB mampu bertahan lama, diteliti, dan diamati semua pengunjung.
\end{abstract}

Kata kunci: Spesimen; Kurator; Museum Zoologi SITH ITB

Korespondensi: Jaenal Ihsan Kaenuwihanulah, PT. Alif Samudra Benua Bandung, Jl. Lurah Abdul Khamid No. 20 Madalangu RT/RW 03/07 Cipacing Jatinangor, Kab. Sumedang Kode Pos (45363) Jawa Barat, Indonesia

Email: ihsaaaann@gmail.com

http://jurnal.unpad.ac.id/informatio

DOI: https://doi.org/10.24198/inf.v1i1.31776

Received: Januari 2021; Accepted: Januari 2021; Published: Januari 2021

(C) Informatio 2021. This is an open access article under the CC BY-SA license 


\title{
Identification and collection storage of Museum Zoologi Sekolah Ilmu dan Teknologi Hayati (SITH) Institut Teknologi Bandung Jatinangor
}

\begin{abstract}
The museum has a role as educational and research facilities for visitors. The Museum of Zoologi SITH ITB is one of the museum that has a collection of both wet and dry specimens. Preserved specimens become museum collections that are vulnarable to fragility or damage. Museum helped us to preserve the animals and change it to specimens so that museum visitors could see it. Thus, this study aims to see how to identify and serve collection at the Museum of Zoologi SITH ITB. The research method used was qualitative with case study approach, and the research subjects were museum head, curators, and museum visitors. The data were collected through interviews, observation, and literature review. According to the research results, museum collections are determined based on the policy of selecting animal species to be used as specimens, preservation and conservation methods (display), as well as taxonomic information. The types of animals chosen are those that have a backbone and no backbone, including invertebrates, fish, amphibians, reptiles, birds and mammals through wet and dry preservation. The conservation of the Museum of Zoology SITH ITB collection is carried out through a process of collection analysis, preservation, labeling, and storage. First, in performing the collection analysis process, curators observe animals to be killed for specimens and writes a permission letter to the authorized institution. Second, in performing preservation, curators preserve wet and dry specimen collections according to their own specimens. Third, in labeling activities, curators label wet and dry specimen collections according to the container placement. Finally, in storage activities curators store different collections of wet and dry specimens. Research on the identification and storage of collections at the Museum Zoologi SITH ITB can assist curators in introducing preserved specimens to visitors. The conclusion of the research is that the curators of the Museum Zoologi SITH ITB play an important role in maintaining the collection and introducing the museum collection to visitors, and this makes the collection of the museum to be long-lasting, researchable, and obserevable for all visitors.
\end{abstract}

Keywords: Specimens; Curators; Museum of Zoologi SITH ITB

\section{PENDAHULUAN}

Secara geografis wilayah Indonesia mulai dari Pulau Sumatra sampai ke Pulau Papua terdiri dari media kehidupan yang umum di antaranya seperti air, udara, dan tanah menjadikan ekosistem alami bagi makhluk hidup fauna di Indonesia. Keanekaragaman fauna di Indonesia menghasilkan peninggalan karya budaya sehingga menjadikan keunikan sebagai identitas bagi setiap daerah. Beragam keanekaragaman hayati fauna yang menghasilkan peninggalan karya budaya harus diwariskan turun temurun hingga generasi selanjutnya. Berdasarkan keanekaragam hayati fauna sebagai hasil karya budaya, manusia harus bertanggung jawab dalam menjaga keanekaragaman hayati.

Museum sebagai fenomena budaya memiliki sejarah yang panjang. Museum telah berubah dari waktu ke waktu seiring perkembangan ilmu pengetahuan dan teknologi, salah satunya ialah jenis museum zoology. Museum isi berisi koleksi yang khusus mempelajari keanekaragaman fauna. Koleksi museum pun makin diperluas sesuai perkembangan ilmu

\footnotetext{
Identifikasi dan penyimpanan koleksi Museum Zoologi Sekolah Ilmu dan Teknologi Hayati (SITH) Institut Teknologi Bandung Jatinangor

(Jaenal Ihsan Kaenuwihanulah, Ninis Agustini Damayani, Rully Khairul Anwar)
} 
zoologi. Museum zoologi menjadi lembaga yang didedikasikan untuk melestarikan koleksi fauna yang mulai terancam hilang dan punah.

Kegiatan dalam menjaga keanekaragaman hayati di museum zoologi ialah kegiatan preservasi dan konservasi, yang berfokus pada kegiatan konservasi ekosistem, genetik dan spesies. Museum zoologi bertugas menyimpan satwa, binatang atau fosil satwa, untuk diawetkan secara utuh, atau bagian-bagian organ dari satwa, misalnya seperti plasenta, jantung, dan organ-organ lain yang dikumpulkan. Museum Zoologi Sekolah Ilmu dan Teknologi Hayati ITB (Museum Zoologi SITH ITB) menjadi museum zoologi yang dikelola universitas, yang didirikan sekitar 1950-an. Ini menjadi museum zoologi tertua kedua setelah Museum Zoologi Bogor sehingga koleksi bidang museum pun banyak dan lengkap. Museum Zoologi SITH ITB dalam memperkaya jumlah koleksi museum telah melakukan upaya kerja sama dan pembelian. Kerja sama telah dilakukan dengan museum dari Amerika dan Eropa melalui mekanisme tukar menukar spesimen koleksi museum, sedangkan pembelian koleksi dari instansi khusus yang menyediakan preparat-preparat spesimen, seperti telur sampai dewasa dalam bentuk awetan. Hal ini dinyatakan oleh kurator museum zoologi.

"Total sekarang yang masuk di database saya sekitar 1027 spesies, Spesimennya sekitar 3000-an lebih. Spesies itu jenis satwanya, Spesimen itu banyaknya. misalnya Spesies burung beo kita punya Spesimen 5 Beo itu unitnya." (Ganjar Cahyadi, personal communication, December 15, 2019).

Saat ini, Museum Zoologi SITH ITB memiliki koleksi museum yang tercatat di database sekitar 1027 spesies dan 3000-an lebih spesimen. Koleksi museum dikelompokkan dalam dua jenis koleksi, yakni koleksi basah yang berasal dari satwa invertebrata laut berupa udang-udangan, kerang, ikan dan satwa-satwa laut lainnya, dan koleksi kering. Koleksi museum sebagian besar berasal dari tahun 1940 hingga 1950-an dari Indonesia timur. Adapun koleksi masterpiece yang dimiliki museum hingga saat ini yaitu koleksi awetan kering harimau sumatra, sebagai satwa spesies satwa endemik (satwa lindungan).

Kegiatan preservasi koleksi yang selama ini dilakukan di Museum Zoologi SITH ITB telah menjadikan satwa yang terancam punah dapat diawetkan dan diperlihatkan kepada pengunjung dari pelbagai kalangan. Hal ini membuat sarana belajar yang menyenangkan bagi pengunjung dalam memahami dunia fauna. Kegiatan pelestarian koleksi merupakan salah satu kegiatan pokok dalam pemeliharaan, perawatan dan penjagaan koleksi agar berumur panjang di museum, perpustakaan, dan lembaga informasi lainnya. Kegiatan preservasi di Museum Zoologi SITH ITB dilakukan seorang kurator, yang berperan penting dalam mengelola museum. Koleksi Museum Zoologi SITH ITB yakni satwa yang diawetkan

Identifikasi dan penyimpanan koleksi Museum Zoologi Sekolah Ilmu dan Teknologi Hayati (SITH) Institut Teknologi Bandung Jatinangor

(Jaenal Ihsan Kaenuwihanulah, Ninis Agustini Damayani, Rully Khairul Anwar) 
rentan terjadi kerusakan karena faktor internal dan eksternal. Hal ini mengingat koleksi yang tersimpan di museum memiliki nilai ilmu pengetahuan, nilai administrasi, nilai informasi, nilai sejarah, nilai budaya, dan kenangan. Sang kurator menuturkan:

"Koleksi di sini berguna untuk ilmu pengetahuan sebagai sumber bahan penelitian khususnya di Departemen Biologi. Kita punya koleksi fosil-fosil satwa dikumpulkan dari sekitar tahun 1960 sampai sekarang yang punya nilai histori." (Ganjar Cahyadi, personal communication, December 15, 2019).

Dengan demikian, koleksi museum perlu dirawat dan dilestarikan untuk mempertahankan keberadaan informasi, dan menjaga usia koleksi agar tetap dapat diakses selama dibutuhkan generasi seterusnya melalui preservasi. Penelitian ini berfokus meneliti koleksi dan penyimpanan koleksi di Museum Zoologi SITH ITB. Adapun beberapa asumsi dasar kegiatan preservasi preventif yang menyatakan, "1) Identifyng what collections are made of and how the information in the has been recorded. 2) Improving the way collections are stored or housed" (Harvey \& Mahard, 2014). Asumsi teori ini adalah kegiatan preservasi preventif dapat terdiri dari identifikasi koleksi dan penyimpanan koleksi. Kegiatan preventif menjadi salah satu kegiatan penting dalam menjaga kelangsungan sebuah lembaga informasi, tidak terkecuali pada museum. Prinsip kegiatan preventif pada dasarnya menjaga koleksi tetap utuh dan tetap dapat digunakan. Museum Zoologi SITH ITB sendiri memiliki kegiatan preservasi preventif yang unik atau khas dibandingkan museum universitas lainnya, di antaranya kegiatan identifikasi koleksi dan penyimpanan koleksi.

Pertama, kegiatan identifikasi koleksi museum. Kegiatan identifikasi koleksi museum merupakan kegiatan pengamatan kerusakan dan ancaman yang membahayakan kondisi fisik koleksi serta media pendukung koleksi museum. Kegiatan identifikasi koleksi museum menjadi tindakan manajemen atau pengaturan program seleksi preservasi museum. Museum Zoologi SITH ITB memiliki kebijakan dalam memperlakukan setiap koleksinya guna koleksi tetap dipertahankan atau dimusnahkan yang telah berdasarkan berbagai pertimbangan. Sebagaimana yang dikatakan kurator, "Perlakuan setiap satwa kita bedakan. Jadi kita spesifik terhadap cara penanganan berbeda tergantung taksanya" (Ganjar Cahyadi, personal communication, December 15, 2019).

Kedua, kegiatan penyimpanan koleksi. Kegiatan penyimpanan merupakan kegiatan mengolah dan menempatkan koleksi museum, berupa penempatan di "Containers, pelabelan, specimen deterioration" (Hartman, 2018). Satwa atau spesimen yang diawetkan ditempatkan pada gelas atau tabung kaca yang berisi cairan kimia. Lalu setiap koleksi diberikan label atau penamaan sebagai identitas koleksi. Hartman (2018) menjelaskan

\footnotetext{
Identifikasi dan penyimpanan koleksi Museum Zoologi Sekolah Ilmu dan Teknologi Hayati (SITH) Institut Teknologi Bandung Jatinangor

(Jaenal Ihsan Kaenuwihanulah, Ninis Agustini Damayani, Rully Khairul Anwar)
} 
sebagian besar spesimen yang telah dikumpulkan dalam metode penyimpanan pada gelas kaca adalah yang terbaik. Metode penyimpanan koleksi di Museum Zoologi SITH ITB seperti ini bertujuan mengurangi penguapan. Selain itu, wadah penyimpanan koleksi awetan basah pun sangat diperhatikan untuk menjaga koleksi tetap utuh. Kurator menceritakan bahwa,

"Wadahnya itu standar museum dan ada seal-nya, idealnya untuk kontaminasi dari luar tidak ada, kemudian penguapan juga tidak ada. Biasanya botolnya bermulut lebar, teknis fungsinya untuk keluar masuk spesimen. Maka standarnya botol ber-sealer dan botol mulutnya berlebar" (Ganjar Cahyadi, personal communication, December 15, 2019).

Secara teknis satwa atau spesimen yang diawetkan, ditempatkan pada gelas atau tabung kaca yang berisi cairan kimia. Selain itu, wadah tersebut menggunakan sealer atau penutup botol yang berguna mencegah penguapan cairan awetan koleksi basah. Dilanjutkan dengan kegiatan perawatan dan perlindungan koleksi. Kegiatan perawatan koleksi Museum Zoologi SITH ITB, yakni perawatan secara fisika dan biologi menggunakan cairan kimia. Kurator menceritakan bahwa, "Sudah ada, dan zaman dulu pengawetan masih pakai formalin untuk koleksi basah" (Ganjar Cahyadi, personal communication, December 15, 2019).

Kegiatan ini dilakukan pada koleksi awetan basah dan awetan kering. Satwa awetan basah atau koleksi basah menggunakan cairan preservatif, yakni cairan alkohol 70\%. Cairan ini memiliki sifat zat antibiotik dan antiseptik yang sesuai untuk pengawetan jangka panjang. Ini dilakukan agar satwa awetan basah tidak terkena bakteri organisme pembusuk yang bisa masuk dan hidup dalam spesimen. Metode ini mengubah kebijakan preventif pengawetan koleksi basah yang dulu menggunakan formalin 4\% pada 1990-an. Adapun perawatan pada koleksi kering menggunakan metode taksidermi, adalah metode pengawetan satwa kering untuk ditampilkan di museum, tanpa menghilangkan bentuk estetika fauna tersebut.

Berdasarkan kegiatan penyimpanan koleksi dan kegiatan perawatan koleksi Museum Zoologi SITH ITB di atas, kurator telah berhasil membuat koleksi museum dapat bertahan hingga saat ini. Satwa yang diawetkan dari tahun 1940-an masih bisa dilihat pengunjung sampai dengan sekarang dalam keadaan utuh, dalam rak pajangan yang telah disusun sedemikian rupa. Hal ini menjadi fenomena yang menarik untuk diteliti. Koleksi museum yang umurnya sudah lama masih bisa dipajang dan dilihat pengunjung museum. Berdasarkan penelitian Fitrianti (2019) naskah kuno di Museum Prabu Geusan Ulun Sumedang diteliti dari segi penelitian kegiatan preventif dan kuratif. Penelitian ini 
memiliki kesamaan penelitian mengenai koleksi museum namun perbedaannya terletak pada objek yang diteliti ialah koleksi di Museum Zoologi SITH ITB berupa awetan koleksi basah dan kering, sedangkan penelitian Fitrianti (2019) berupa naskah kuno.

Penelitian mengenai koleksi Museum Zoologi menjadi penelitian baru yang menggambarkan perawatan pada koleksi spesimen. Kurator berperan penting dalam menjaga keutuhan dan keberlangsungan spesimen agar dapat terjaga sehingga dapat dilihat oleh pengunjung dari segala usia. Maka, penelitian ini memiliki rumusan masalah dalam membahas mengapa dan bagaimana identifikasi dan penyimpanan koleksi yang dilakukan di Museum Zoologi SITH ITB. Adapun tujuan penelitian ini ialah untuk mengetahui identifikasi dan penyimpanan koleksi yang dilakukan di Museum Zoologi SITH ITB. Koleksi spesimen yang berumur puluhan tahun menjadi daya tarik pengunjung untuk datang ke museum. Kurator sebagai pemegang kunci museum telah membantu melestarikan koleksi spesimen dari berbagai ancaman kepunahan.

\section{METODE PENELITIAN}

Penelitian ini menggunakan jenis penelitian kualitatif dengan metode studi kasus. Penelitian kualitatif sebagaimana yang diungkapkan menurut Sugiyono (2013) adalah metode yang digunakan untuk meneliti pada kondisi objek yang alamiah. Peneliti adalah instrumen kunci, teknik pengumpulan data dilakukan secara triangulasi (gabungan), analisis data bersifat induktif. Hasil penelitian kualitatif lebih menekankan makna daripada generalisasi. Objek penelitian dalam penelitian kualitatif mengacu pada situasi sosial yang terdiri atas tiga elemen utama di antaranya, "tempat (place), pelaku (actors), dan aktivitas (activity)" (Sugiyono, 2013).

Situasi sosial tersebut dapat terjadi di rumah, tempat kerja, sekolah, wilayah dalam suatu negara atau apa saja. Situasi sosial tersebut dinyatakan sebagai objek penelitian yang ingin dipahami secara lebih mendalam mengenai apa yang terjadi di dalamnya. Objek penelitian ini yakni koleksi dan penyimpanan koleksi di Museum Zoologi Institut Teknologi Bandung. Kegiatan yang dimaksud adalah mengapa dan bagaimana koleksi dan penyimpanan koleksi di Museum Zoologi SITH ITB. Peneliti mengkaji objek penelitian tersebut berdasarkan dan sesuai kajian teori dan konseptual yang berlandaskan dengan teori preservasi.

Berdasar pengertian metode kualitatif menurut Sugiyono (2013), metode kualitatif dikatakan sebagai metode naturalisitik karena objek dalam penelitian ini adalah objek yang alamiah atau natural setting. Obyek pada penelitian ini adalah koleksi dan penyimpanan koleksi di Museum Zoologi Institut Teknologi Bandung. Maka dalam penelitian ini

\footnotetext{
Identifikasi dan penyimpanan koleksi Museum Zoologi Sekolah Ilmu dan Teknologi Hayati (SITH) Institut Teknologi Bandung Jatinangor

(Jaenal Ihsan Kaenuwihanulah, Ninis Agustini Damayani, Rully Khairul Anwar)
} 
tentunya murni tidak ada unsur kesengajaan manipulasi. Penelitian ini menggunakan metode studi kasus sebagai sarana penulis untuk dapat memetakan fenomena penelitian dalam kajian permasalahan berdasarkan pada suatu set kondisi kasus tertentu. Penelitian studi kasus memusatkan diri secara intensif terhadap satu objek tertentu, dengan cara mempelajarinya sebagai suatu kasus yang unik dan memiliki kekhasan sebagaimana diungkapkan Yin (2015) bahwa, "Studi kasus adalah suatu inkuisi empiris yang menyelidiki fenomena di dalam konteks kehidupan nyata, bilamana batas-batas antara fenomena dan konteks tak tampak dengan tegas; dan di mana multisumber bukti dimanfaatkan."

Studi kasus pada penelitian ini menjadikan kegiatan preservasi preventif melalui koleksi dan penyimpanan koleksi di Museum Zoologi SITH ITB sebagai gambaran dari keberadaan kasus yang dipelajari tentang "bagaimana" dan "mengapa" dari kekhasan kasus tersebut. Sebagaimana diungkapkan Yin (2015) bahwa, "Untuk studi kasus, kelebihan tampak bilamana pertanyaan 'bagaimana' dan 'mengapa' akan diarahkan ke serangkaian peristiwa kontemporer, di mana penelitinya hanya memiliki peluang yang kecil sekali atau tidak mempunyai peluang sama sekali untuk melakukan kontrol terhadap peristiwa tersebut."

Studi kasus sebagaimana dijelaskan di atas lebih menunjukkan pada upaya untuk lebih memaknai permasalahan penelitian dengan berdasarkan pada kasus tertentu di mana dari kekhasan kasusnya tersebut dianggap memiliki gambaran akan tipikal kasus lainnya atau justru tidak. Studi kasus pada penelitian ini ditujukan untuk mempelajari kasus tunggal yang berkaitan dengan kegiatan preservasi preventif di Museum Zoologi SITH ITB. "Studi kasus instrumental (instrumental case study), jenis ini digunakan untuk meneliti suatu kasus tertentu agar tersaji sebuah perspektif tentang isu atau perbaikan suatu teori. Dalam hal ini, kasus tidak menjadi minat utama; kasus memerankan peranan suportif, yang memudahkan pemahaman kita tentang sesuatu yang lain... Suatu kasus bisa dipandang sebagai sebuah gambaran tipikal bagi kasus-kasus lain, atau justru tidak. Pemilihan sebuah kasus lebih disebabkan karena hasrat kita untuk meningkatkan pemahaman tentang minatminat yang lain tersebut" (Denzin \& Lincoln, 2009).

Studi kasus instrumental membuka peluang peneliti untuk mempelajari kasus yang tengah diamati sekarang dengan mengkaji dari kekhasan kasus lainnya karena adanya peluang bahwa kasus lainnya dapat menjadi tipikal bagi kasus yang diamati sekarang. Peneliti memfokuskan satu kekhasan kasus sebagai objek penelitian, sedangkan pembanding dari kasus-kasus serupa lainnya tidak diamati melainkan sebagai bentuk pengembangan atas adanya kesamaan kasus dengan yang peneliti amati sekarang ini. Meskipun pada praktik pelaksanaannya, studi kasus juga memungkinkan untuk melakukan 
kajian pada lebih dari satu kasus tertentu, tetapi metode dari studi kasus ini tetap merujuk pada kasus tunggal dengan menempatkan kegiatan preservasi preventif melalui koleksi dan penyimpanan koleksi di Museum Zoologi Institut Teknologi Bandung. Kurator di Museum Zoologi ITB sendiri, telah berhasil membuat koleksi museum dapat bertahan hingga saat ini. Satwa yang diawetkan dari tahun 1940-an masih bisa dilihat pengunjung sampai dengan sekarang dalam keadaan utuh, dalam rak pajangan yang telah disusun sedemikian rupa. Hal ini menjadi fenomena yang menarik untuk diteliti. Koleksi museum yang umurnya sudah lama masih bisa dipajang dan dilihat pengunjung museum. Penelitian ini akan berfokus dalam meneliti kegiatan preventif di Museum Zoologi ITB, melalui metode penelitian kualitatif melalui pendekatan studi kasus.

Subjek dalam penelitian ini yakni merujuk pada bagian operasional Museum Zoologi Institut Teknologi Bandung yang menangani seluruh kegiatan preservasi museum yang terdiri dari Kepala Museum Zoologi SITH ITB, kurator, dan pengunjung museum. Objek penelitian ini yakni kegiatan preservasi preventif di Museum Zoologi Institut Teknologi Bandung. Kegiatan yang dimaksud adalah bagaimana tindakan preventif dalam preservasi koleksi yang ada di Museum Zoologi SITH ITB. Peneliti akan mengkaji objek penelitian tersebut berdasarkan sesuai kajian teori dan konseptual yang berlandaskan dengan teori preservasi. Penelitian ini memerlukan data yang dijadikan sebagai objek untuk menjadi sumber kajian. Sumber data dapat diklasifikasikan menjadi dua bagian, yaitu data primer dan data sekunder sebagaimana diungkapkan Moleong (2011), bahwa sumber data utama (primer) dalam penelitian kualitatif ialah kata-kata, dan tindakan, selebihnya (sekunder) adalah data tambahan seperti dokumen dan lain-lain. Sumber data primer dalam penelitian ini didapatkan dari wawancara dengan informan maupun melalui observasi dalam mempelajari perilaku dari orang-orang yang memiliki keterkaitan dengan kegiatan preservasi preventif di Museum Zoologi Institut Teknologi Bandung.

Sumber data primer melalui wawancara dilakukan dengan informan-informan yang memiliki pengalaman serta pengetahuan dalam menjelaskan fenomena penelitian terkait dengan preservasi museum zoologi. Informan dalam penelitian ditentukan sebagai pihak yang dijadikan sebagai sumber informasi, di mana peneliti dapat menentukan informan dan jumlahnya sesuai dengan kebutuhan penelitian, sebagaimana diungkapkan Sarwono (2006) bahwa banyak sedikitnya orang yang akan digunakan untuk menjadi informan dalam penelitian kita tergantung pada cakupan masalah penelitian yang akan dilakukan. Peneliti dapat menentukan informan dan jumlahnya dengan berdasarkan pada kepentingan kedalaman penelitian. Pemilihan subjek penelitian kualitatif berasal dari adanya para pelaku sebagai bagian dari fenomena yang tidak bergantung pada jumlahnya saja tetapi

\footnotetext{
Identifikasi dan penyimpanan koleksi Museum Zoologi Sekolah Ilmu dan Teknologi Hayati (SITH) Institut Teknologi Bandung Jatinangor

(Jaenal Ihsan Kaenuwihanulah, Ninis Agustini Damayani, Rully Khairul Anwar)
} 
lebih difokuskan pada kualitas informan melalui teknik purposive, sebagaimana diungkapkan Rakhmat (2012) bahwa, purposive sampling digunakan dengan memilih orang-orang tertentu karena dianggap berdasarkan penilaian tertentu.

Sumber data sekunder dalam penelitian ini didapatkan dari berbagai sumber dokumentasi yang terkait dengan Museum Zoologi ITB yang dapat berasal dari informan internal museum Zoologi ITB, maupun dari sumber-sumber lainnya. Data sekunder juga dapat diperoleh dari informasi-informasi literatur seperti jurnal, penelitian terdahulu, berita dan informasi online yang dinilai memiliki keterkaitan dengan penelitian serta dapat dipertanggungjawabkan informasinya. Peneliti dalam teknik pengumpulan data melakukan observasi, wawancara dan studi literatur. Teknik analisis data menggunakan reduksi data, penyajian data, dan verification. Sugiyono (2013) mengatakan bahwa reduksi data sebagai proses pemilihan, pemusatan perhatian pada penyederhanaan, pengabstrakan, dan transformasi data yang muncul dari catatan-catatan peneliti di lapangan. Selama pengumpulan data berlangsung, terjadi tahapan reduksi selanjutnya membuat ringkasan, mengode, menelusur tema, membuat gugus-gugus, membuat partisi, dan penyempitan ringkasan data lainnya. Reduksi data/proses transformasi ini berlanjut terus sesudah penelitian lapangan, sampai laporan akhir lengkap tersusun.

Teknik penyajian data digambarkan melalui rangkaian kalimat yang disusun secara logis dan sistematis agar mudah dipahami. Penyajian data ini merupakan serangkaian upaya peneliti dalam menyampaikan hasil-hasil temuan di lapangan yang telah melalui tahap reduksi data. Penyajian data ini merupakan upaya peneliti dalam menampilkan hasil penelitian sebagaimana pemahamannya dalam mengonsepkan jawaban-jawaban penelitian. Lalu verification merupakan hasil akhir yang ingin disampaikan peneliti mengenai hal-hal yang menjadi perhatian peneliti. Verifikasi merupakan tinjauan ulang pada catatan-catatan lapangan dengan peninjauan kembali berbagai upaya penyusunan data melalui berbagai penyeleksian data yang didapat agar memenuhi unsur keseluruhan kebutuhan hasil penelitian. Penelitian ini dilakukan di Museum Zoologi SITH ITB pada Desember 2019 hingga Juli 2020.

\section{HASIL DAN PEMBAHASAN}

\section{a. Identifikasi Koleksi Museum Zoologi SITH ITB}

Saat pertama kali dibangun, Institut Teknologi Bandung (ITB) bernama Technische Hoogeschool (THS) diresmikan pada 3 Juli 1920 (Katam, 2009). Hadirnya perguruan tinggi ini, menjadikan para peneliti dari Belanda yang sering mencari spesimen satwa memiliki laboratorium khusus untuk menyimpan spesimen satwa yang diawetkan. Sekitar tahun 
1940-an, peneliti Belanda bahkan mengumpulkan spesimen satwa dari berbagai daerah di Indonesia. Hal ini seperti yang diungkapkan informan:

"Depertemen Biologi itu, tuh, kaya semacam wadahnya untuk peneliti-peneliti dari luar tentang keanekaragaman fauna." (Ganjar Cahyadi, personal communication, September 26, 2019).

Adanya Departemen Biologi ITB, menarik para peneliti Belanda dan peneliti dari Eropa lainnya untuk bekerja sama. Sepuluh tahun kemudian, dibangun Museum Zoologi SITH ITB. Koleksi spesimen satwa yang sebelumnya dikumpulkan para peneliti Belanda, lalu dapat terkumpul di Museum Zoologi SITH ITB sehingga terdapat koleksi spesimen satwa yang tahun diawetkannya berada di bawah tahun 1920. Koleksi ini termasuk ke dalam koleksi pribadi peneliti Belanda tersebut. Menurut salah seorang informan spesimen satwa yang terkumpul sekitar tahun 1940 hingga 1950-an ialah satwa intervebrata laut seperti udang-udangan, kerang, ikan yang kebanyakan koleksi dari Indonesia timur (Ambon dan Kepulauan Aru. Seiring waktu bertambah, spesimen satwa yang terkumpul semakin banyak. Bahkan pada tahun 1960-an, staf pengajar Departemen Biologi bidang zoologi dan taksonomi satwa melakukan ekspedisi dari Sumatra, Jawa, Kalimantan, Sulawesi sampai kepulauan kecil di Nusa Tenggara. Koleksi spesimen satwa di tahun 1960an menjadi koleksi khusus hasil ekspedisi beberapa staf Pengajar Departemen Biologi pada waktu itu.

Museum Zoologi SITH ITB tidak hanya sebagai tempat penyimpanan spesimen satwa yang diawetkan saja. Museum ini menjadi salah satu fasilitas bagi mahasiswa dan masyarakat luar untuk mempelajari bidang zoologi dan taksonomi. Hal ini sesuai dengan visi Museum Zoologi sebagai, "Sarana pendukung dalam memperlancar pendidikan dan pengajaran biologi di SITH ITB" (Museum Zoologi SITH ITB, 2020a). Museum ini memfasilitasi proses pendidikan bagi mahasiswa bidang biologi SITH ITB. Museum Zoologi SITH ITB memiliki koleksi satwa yang diawetkan (spesimen) dari tahun 1909 hingga 2020. Salah seorang informan menjelaskan jika spesimen ini bersumber dari koleksi pribadi, koleksi kebun binatang, spesimen dari rumah sakit bersalin serta hadiah dari peneliti Amerika Serikat dan Eropa. Koleksi museum yang berumur 1909, menjadi koleksi paling tua yang bersumber dari koleksi pribadi para peneliti Belanda pada zaman itu. Para peneliti ini banyak melakukan ekspedisi dan menyimpan spesimen satwa di lokasi ITB Bandung dulu, contohnya burung pelatuk.

Para peneliti Amerika Serikat dan Eropa pun selain memberikan koleksi sebagai hadiah, mereka melakukan tukar menukar koleksi dengan museum ini. Sesuai perkataan narasumber:

\footnotetext{
Identifikasi dan penyimpanan koleksi Museum Zoologi Sekolah Ilmu dan Teknologi Hayati (SITH) Institut Teknologi Bandung Jatinangor (Jaenal Ihsan Kaenuwihanulah, Ninis Agustini Damayani, Rully Khairul Anwar)
} 
"Terus ada juga mekanisme tukar menukar dari museum Amerika dan Eropa. Kita punya spesimen apa, sebagai contoh kita punya ini, ya, tukar menukar aja. Museum Zoologi SITH ITB pun melakukan, "Beli dari instansi khusus yang menyediakan preparat-preparat spesimen kaya misalnya telur sampai dewasa dalam bentuk awetan"(Ganjar Cahyadi, personal communication, September 26, 2019).

Sehubungan dengan penuturan informan, preparat artinya, "Bahan yang disiapkan secara kimiawi” (Pusat Bahasa, 2020a). Museum Zoologi SITH ITB membeli bahan untuk awetan satwa secara basah dan kering. Sesuai Cahyadi (2020) dikatakan bahwa, "Museum Zoologi SITH ITB memiliki total spesimen sebanyak 2849 spesimen dengan total spesies sebanyak 1045 spesies (per 20 Juli 2020).” Adapun koleksinya terdiri dari spesimen invertebrata, ikan, amfibi, reptil, burung, dan mamalia. Pertama, spesimen invertebrata atau satwa bertulang belakang berjumlah, "700 eksemplar dari 277 spesies" (Cahyadi, 2020d) yang diklasifikasikan menjadi filum/subfilum atau, "Golongan besar dalam klasifikasi satwa dan tumbuhan yang mempunyai persamaan sifat dasar tertentu, yang masih terbagi lagi menjadi subfilum, kelas, ordo, famili, genus, dan spesies" (Badan Pengembangan dan Pembinaan Bahasa (Pusat Bahasa, 2020b)

\section{Spesimen Invertebrata}

Tabel 1. Klasifikasi Spesimen Invertebrata

\begin{tabular}{ccc}
\hline Filum/subfilum & Jumlah spesimen & Jumlah spesies \\
\hline Annelida (cacing bersegmen) & 96 & 26 \\
Cnidaria (e.g. ubur-ubur, koral) & 55 & 35 \\
Crustacea (e.g. kepiting, udang-udangan) & 139 & 52 \\
Echinodermata (e.g. bintang laut, & 41 & 25 \\
teripang, bulu babi) & & \\
Hexapoda (e.g. serangga) & 85 & 25 \\
Mollusca (e.g. siput, kerang, cumi-cumi, & 179 & 53 \\
gurita) & & \\
Myriapoda (e.g. kaki seribu, kelabang) & 33 & 9 \\
Invertebrata lain & 72 & 52 \\
Total & 700 & 277 \\
\hline
\end{tabular}

Sumber: Cahyadi (2020).

Sesuai data ini, invertebrata dari laut menjadi jumlah spesimen yang banyak dimiliki Museum Zoologi SITH ITB, seperti filum crustacea berjumlah 139 dan filum mollusca berjumlah 179. Hal ini karena Indonesia sebagian besar wilayahnya lautan yang menyimpan koleksi invertebrata laut yang tidak terhingga. Semua filum/subfilum 
invertebrata di Museum Zoologi SITH ITB diawetkan secara basah dan kering. Koleksi invertebrata yang diawetkan basah direndam dalam cairan alkohol 70\% contohnya belalang (romalea microptera). Spesimen invertebrata yang diawetkan secara kering, "Cangkang (pada Mollusca dan Crustacea), karang batu (pada Cnidaria) dan tubuh utuh (pada Hexapoda)" (Cahyadi, 2020d). Selain itu, invertebrata awetan kering di museum ini bertambah dari datangnya cangkang siput (brotia sumatrensis) yang berasal dari, "Sungai Ataghan Merlang, Desa Karang Dapo yang baru saja diteliti Nina K. D. Putri, salah satu mahasiswi Sekolah Tinggi Farmasi Indonesia untuk penelitian Tugas Akhir" (Cahyadi, 2020d).

\section{Spesimen Ikan}

Kedua, spesimen ikan. Spesimen ini memiliki nama latin ichthyofauna, dan tersimpan di Museum Zoologi SITH ITB, "457 eksemplar dari 301 spesies” (Cahyadi, 2020c). Kurator membagi spesimen ikan menjadi beberapa ordo. Kurator mengawetkan spesimen ikan dengan melakukan awetan basah dan awetan kering. Bloch (1790) dalam Cahyadi (2020) menulis, "Spesimen ikan yang tersimpan di Museum Zoologi SITH ITB hampir semuanya berupa awetan basah yang direndam dengan alkohol $70 \%$ serta formalin $4 \%$. Awetan kering berupa artikulasi rangka kepala dari beberapa spesimen seperti ikan kakap putih [...] terdapat di museum ini." Sebagian besar spesimen ikan diawetkan secara basah menggunakan cairan alkohol. Adapun cairan formalin yang berjumlah $4 \%$ merupakan sisa pengawetan spesimen zaman dulu.

Spesimen ikan yang diawetkan secara kering pun hanya terbatas pada rangka kepala ikan. Pengawetan ikan secara kering hampir sama dengan cara pengawetan pada mamalia, yakni harimau. Ketika pengawetan harimau, kurator mengeluarkan daging, organ dalam, dan tulang, sedangkan dalam pengawetan ikan kurator hanya mengeluarkan organ dalam dan daging. Tulang yang membentuk kepala ikan dikuatkan kembali menggunakan beberapa penyangga untuk menahan agar tidak roboh.

\section{Spesimen Amfibi}

Spesimen ketiga yang terdapat pada koleksi Museum Zoologi SITH ITB adalah amfibi. Saat ini, spesimen amfibi, "Berjumlah 882 eksemplar dari 96 spesies" (Cahyadi, 2020a). Spesimen di museum ini dapat dikelompokkan menjadi beberapa ordo dan famili. Narasumber mengatakan bahwa, "Koleksi basah misalnya amfibi [...] yang seluruh tubuhnya kita awetkan untuk pengamatan atau penelitian" (Ganjar Cahyadi, personal communication, September 26, 2019). Sebagian besar spesimen amfibi diawetkan secara

\footnotetext{
Identifikasi dan penyimpanan koleksi Museum Zoologi Sekolah Ilmu dan Teknologi Hayati (SITH) Institut Teknologi Bandung Jatinangor

(Jaenal Ihsan Kaenuwihanulah, Ninis Agustini Damayani, Rully Khairul Anwar)
} 
basah menggunakan rendaman alkohol 70\% sebagai proses belajar dan penelitian. Beberapa pengunjung anak-anak sekolah, yang menerima materi pelajaran biologi merasa terbantu dengan hadirnya contoh langsung spesimen amfibi.

\section{Spesimen Reptil}

Koleksi spesimen selanjutnya atau yang keempat adalah reptil. Museum Zoologi SITH ITB memiliki spesimen reptil berjumlah, "452 eksemplar dari 149 spesies" (Cahyadi, 2020g). Di mana spesimen reptil diawetkan secara basah dan kering.

Spesimen reptil yang diawetkan basah menggunakan rendaman alkohol $70 \%$ atau formalin $4 \%$. Seperti reptil bernama simotes purpuracens. Identitas dalam tabung gelasnya tertulis Karimon Djawa V-1926. Spesimen reptil ini ditemukan di Karimun Djawa (sekarang Kepulauan Karimunjawa) dan diawetkan pada tahun 1926. Spesimen reptil ini masih bertahan walaupun 94 tahun berlalu karena kandungan alkohol atau formalin. Spesimen yang diawetkan kering berisi, "Artikulasi rangka kepala dari beberapa spesimen seperti buaya muara (srocodylus porosus schneider, 1801) serta berupa opsetan dari beberapa spesies seperti buaya sinyulong (tomistoma schlegelii (Müller,1838)), biawak (varanus salvator (Laurenti, 1768)), penyu sisik (eretmochelys imbricata (Linnaeus, 1766)), dan penyu lekang (lepidochelys olivacea (Eschscholtz, 1829)" (Cahyadi, 2020g).

\section{Spesimen Burung}

Spesimen kelima dari koleksi Museum Zoologi SITH ITB yaitu spesimen burung. Saat ini spesimen burung yang diawetkan, "Berjumlah 167 eksemplar dari 140 spesies" (Cahyadi, 2020b). Spesimen burung yang diawetkan ini sebagian besar diawetkan secara kering yang sebelumnya direndam menggunakan cairan alkohol 70\%. Kurator masih mengumpulkan dan memasukkan data spesimen burung. Hal ini disebabkan perpindahan lokasi gedung Museum Zoologi SITH ITB dari Bandung ke Jatinangor. Museum Zoologi SITH ITB memiliki beberapa jenis burung yang telah diawetkan secara kering, mulai dari burung elang sebagai burung pemangsa, burung cendrawasih, burung pemakan serangga, dan burung beo. Sebagian besar burung yang diawetkan ini merupakan burung yang mulai punah atau langka. Pengunjung dapat melihat spesimen burung-burung langka di museum walaupun kondisinya sendiri burung tersebut sudah tidak dapat ditemukan lagi.

\section{Spesimen Mamalia}

Spesimen keenam yakni mamalia. Museum Zoologi SITH ITB memiliki spesimen mamalia, "Berjumlah 185 eksemplar dari 77 spesies" (Cahyadi, 2020f). Kurator 
mengawetkan spesimen ini dengan cara kering menggunakan rendaman alkohol $70 \%$. Bentuk awetannya sendiri, berupa bentuk opsetan atau artikulasi rangka. Mamalia yang diawetkan berbentuk opsetan, yakni mengeluarkan organ dalam termasuk lemak di dalamnya. Adapun mamalia yang diawetkan berbentuk artikulasi rangka biasanya mamalia yang berukuran besar dan tulang rangka yang kuat.

\section{b. Penyimpanan koleksi di Museum Zoologi SITH ITB}

Kegiatan penyimpanan koleksi di Museum Zoologi SITH ITB dipaparkan mulai dari proses analisis koleksi, pengawetan, pelabelan, dan penyimpanan. Peneliti melihat bahwa tiap spesimen memiliki jenis yang berbeda sehingga kurator menanganinya pun sesuai karakteristik satwa tersebut. Kurator menangani sendiri proses analisis koleksi, pengawetan, pelabelan, dan penyimpanan koleksi Museum Zoologi SITH ITB. Kurator pun dituntut untuk menguasai pengelolaan dan pengolahan koleksi di museum ini. Pertama, proses analisis koleksi. Langkah pertama ialah Museum Zoologi SITH ITB menetapkan satwa yang akan diawetkan. Kurator apabila akan mengawetkan satwa yang dilindungi negara maka harus membuat surat ijin resmi dari Kementrian Lingkungan Hidup dan Kehutanan atau Balai Besar Konservasi Sumber Daya Alam (BBKSDA) Jawa Barat sesuai tempat satwa tersebut berada. Narasumber menjelaskan:

"Kita mengurus izin segala macam koleksi dari kementerian, misalnya seperti di tempat area konservasi, klo misalnya engga ya kita bisa langsung koleksi" (Ganjar Cahyadi, personal communication, September 26, 2019).

Berkaitan dengan satwa yang dibunuh untuk koleksi museum terdapat dalam Undang-Undang Republik Indonesia Nomor 5 Tahun 1990 tentang Konservasi Sumber Daya Alam Hayati dan Ekosistemnya, yang menjelaskan di Pasal 21 Ayat (2), "Setiap orang dilarang untuk menangkap, melukai, membunuh, menyimpan, memiliki, memelihara, mengangkut, dan memperniagakan satwa yang dilindungi dalam keadaan hidup (UU RI No. 5 , 1990). Setiap warga negara Indonesia tidak boleh melukai, membunuh, dan memelihara satwa yang dilindungi negara. Kemudian Pasal 22 Ayat (1) menambahkan bahwa, "Pengecualian dari larangan sebagaimana dimaksud dalam Pasal 21 hanya dapat dilakukan untuk keperluan penelitian, ilmu pengetahuan, dan/atau penyelamatan jenis tumbuhan dan satwa yang bersangkutan" (UU RI No. 5, 1990). Mengingat peraturan perundang-undangan ini, Museum Zoologi SITH ITB memiliki legalitas dalam membunuh satwa karena digunakan untuk keperluan pendidikan dan penelitian. Setelah proses surat izin mematikan satwa selesai, kurator dan tim Museum Zoologi SITH ITB membunuh satwa tersebut. Narasumber menjelaskan:

\footnotetext{
Identifikasi dan penyimpanan koleksi Museum Zoologi Sekolah Ilmu dan Teknologi Hayati (SITH) Institut Teknologi Bandung Jatinangor

(Jaenal Ihsan Kaenuwihanulah, Ninis Agustini Damayani, Rully Khairul Anwar)
} 
"Setelah itu, Kita ada proses killing (membunuh) tergantung dengan jenis spesimennya. Klo kayak serangga pakai killing jar wadah berisi cairan pembius dimasukan ke situ. Setelah mati baru diawetkan. Terus klo amfibi juga sama pakai cairan pembius. Klo reptilia disuntikan ke batang otak atau ke jantung. Klo ikan dimasukan pakai cairan pembiusnya. Jadi beda-beda tiap satwa yang akan diawetkan itu cara preservasinya." (Ganjar Cahyadi, personal communication, September 26, 2019).

Setelah menetapkan satwa yang akan dimatikan, maka kurator dan tim Museum Zoologi SITH ITB mematikan satwa tersebut. Proses mematikan satwa ditangani berbeda sesuai jenis satwanya, misalnya satwa invertebrata serangga yang dimatikan menggunakan cairan pembius (killing jar), satwa reptil menggunakan cairan pembius ke otak, dan satwa ikan dipisahkan dulu ke tempat yang berbeda lalu dibius ke dalam cairan yang dihisapnya. Proses mematikan satwa selesai, maka kurator melakukan proses pengawetan.

\section{c. Proses Pengawetan}

Kedua, proses pengawetan. Museum Zoologi SITH ITB memiliki dua jenis pengawetan satwa melalui pengawetan basah dan kering. Pengawetan koleksi secara basah menggunakan cairan kimia. Narasumber menuturkan:

"Setelah dimatikan terus difiksasi menggunakan formalin 4\%, membentuk spesimen yang alami, klo katak nemplok klo ikan siribnya terbuka. Itu untuk mempermudah pengamatan dan identifikasi spesimen. Kita harus membentuk sedemikian rupa agar si spesimen itu kita bisa pakai terus menerus. Jadi ciri-ciri yang bisa penentu jenis spesies atau penentu marga itu kita display kita tunjukkan sedemikian rupa agar bisa mudah diamati oleh siapa saja” (Ganjar Cahyadi, personal communication, September 26, 2019).

Satwa akan diawetkan secara basah atau kering sesuai jenis satwa tersebut. Satwa ikan dan amfibi akan diawetkan secara basah menggunakan cairan kimia, contohnya formalin berjumlah $4 \%$. Namun, cairan formalin sendiri kini sudah mulai dikurangi. Satwa yang diawetkan dulu masih menggunakan formalin. Padahal, formalin sendiri memiliki senyawa yang tidak bagus untuk kesehatan. Maka, kurator menggunakan alkohol sebagai pengganti cairan pengawet spesimen basah. Alkohol membantu mengawetkan dalam jangka panjang karena bersifat antibiotik dan antiseptik untuk menghindari bakteri. 


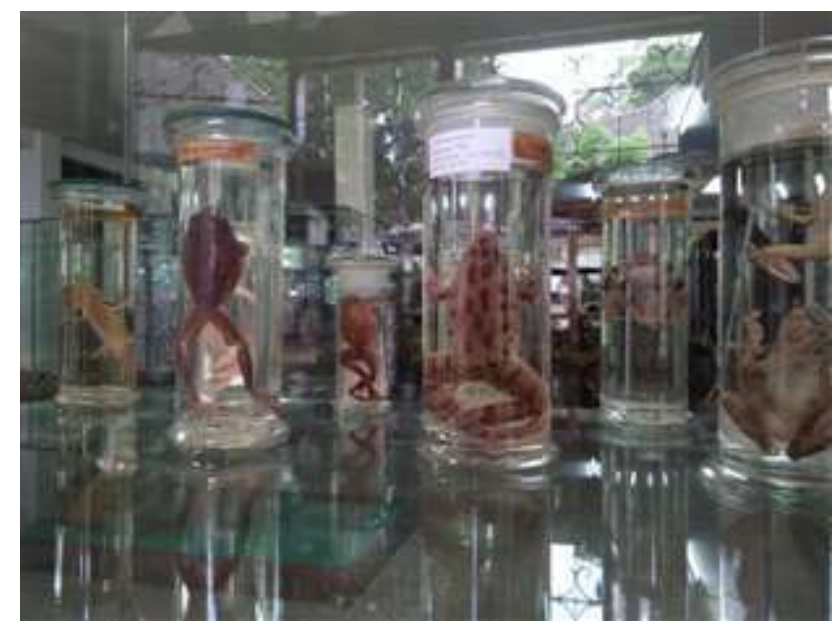

Gambar 1. Contoh Spesimen Awetan Basah

Sumber: Cahyadi (2020)

Satwa yang diawetkan secara kering diambil dari tulang (artikulasi rangka) dan kulit (opsetan). Satwa yang diawetkan kering yang diambil tulangnya saja dapat membentuk sebuah kerangka. Setelah satwa mati, kurator menguliti kulit satwa sampai bersih (maserasi). Kemudian kurator merendam kerangka tulang untuk mengeluarkan lemak, mengeringkan kerangka tulang, dan melakukan pelabelan.

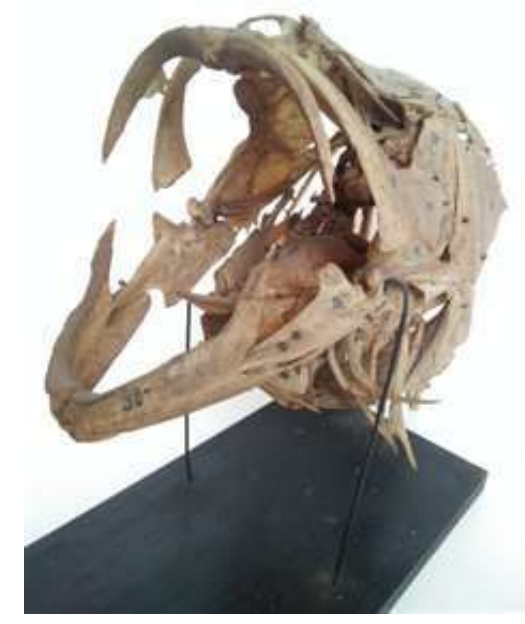

Gambar 2. Spesimen Kepala Ikan Kakap yang Diawetkan Kering Berbentuk Artikulasi Rangka Sumber: Cahyadi (2020c)

Satwa yang diawetkan secara kering ialah mengeluarkan organ dari dalam tubuh satwa tersebut atau disebut taksidermi. Kurator sebelum mengambil organ dalam satwa yang akan diwetkan, terlebih dahulu mengukur semua ukuran tubuh satwa tersebut, misalnya lingkar paha dan lingkar kepala. Lalu kurator mengambil organ dalam, daging, dan tulang dari tubuh satwa. Apabila kurator memiliki ketertarikan mengawetkan organ 
dalam, maka organ dalam tersebut akan diambil. Kurator kemudian mengambil kulit satwa secara hati-hati, tidak boleh sobek. Teknik pemotongan kulit satwa sendiri dimulai dari perut hingga ke leher untuk menghindari kulit tersobek. Setelah itu, kurator menghilangkan lemak dalam kulit karena lemak memunculkan bakteri pembusuk. Kulit akan awet apabila tidak terjadi pembusukan sehingga kulit harus bersih dari lemak.

Kurator lalu melakukan proses pembersihan kulit lalu mengeringkannya. Setelah kulit kering, kurator memasukkan kulit ke dalam rangkanya. Kurator membuat rangka sesuai ukuran proporsional tubuh satwa tersebut dari kawat. Kurator menceritakan bahwa dulu isi rangka satwa yang diawetkan menggunakan kapas atau serbuk kayu. Namun, sekarang isi rangka menggunakan bahan polystyrene, bentuk padat plastik menyerupai gabus. Kurator menggambarkan kepala satwa langsung dalam bahan tersebut. Kemudian, kulit dipasangkan ke dalam rangka lalu dijahit.

\section{d. Proses pelabelan}

Ketiga, proses pelabelan. Setelah satwa selesai diawetkan secara basah dan kering, kurator lalu melakukan pelabelan terhadap koleksi tersebut. Pelabelan merupakan kegiatan mengidentifikasi dan menuliskan data koleksi tersebut. Data ini terdiri dari nama jenis, suku atau nama latin koleksi, nama kolektor dan tanggal pengambilan, nama identifikator dan tanggal identifikasi, lokasi pengambilan koleksi, jumlah eksemplar, dan ukuran. Kadangkala data saat pelabelan dapat bertambah atau berkurang tergantung perubahan, misalnya ada penambahan nomor katalog, koordinat, tanggal pengambilan, dan alat yang digunakan (Pratiwi, 2006).

Data koleksi di Museum Zoologi SITH ITB yang jumlahnya banyak pernah hilang. Hal ini karena data lama koleksi sulit ditemukan, kurator sebelumnya telah meninggal dan tidak menyimpan petunjuk lokasi data koleksi. Kurator akhirnya melakukan pendataan ulang koleksi Museum Zoologi SITH ITB. Kurator pun menetapkan standar input data spesimen, dengan selalu memasukkan nama kolektor, keterangan pengambilan koleksi, jumlah, dan status jenis koleksi baru ditemukan atau jenis koleksi lama. Kurator konsisten mencatat data saat pelabelan agar data spesimen museum lengkap, memudahkan proses memasukkan data ke database, memudahkan penyimpanan disimpan, dan memudahkan temu kembali informasinya ke pengunjung museum.

\section{e. Proses Penyimpanan}

Keempat, proses penyimpanan. Koleksi Museum Zoologi SITH ITB menyimpan koleksi sesuai jenis awetan basah dan awetan kering. Koleksi awetan basah disimpan ke dalam botol bertutup, botol dengan permukaan mulutnya yang lebar, dan penggantian 
cairan formalin ke alkohol. Hal ini sesuai penuturan narasumber bahwa standar botol bersealer dan botol mulutnya lebar. Standar penyimpanan koleksi basah ialah koleksi disimpan dalam botol kaca menggunakan penutup botol bahan kaca. Hal ini dilakukan agar menghindari penguapan dalam botol. Kurator akan memasukkan spesimen ke dalam botol, lalu mengisi cairan alkohol hingga memenuhi isi botol. Sifat cairan alkohol mudah menguap sehingga kurator harus mengisi cairan memenuhi botol dan memeriksanya setiap saat. Adapun botol menggunakan penutup botol dan bersegel menghindari kontaminasi atau jamur dari luar, dan mengurangi penguapan. Kurator juga memilih botol yang permukaannya lebar memudahkan keluar masuk spesimen. Spesimen memang memiliki ukuran tubuh yang berbeda-beda sehingga kurator menggunakan botol kaca yang ukuran dalam botolnya lebih besar.

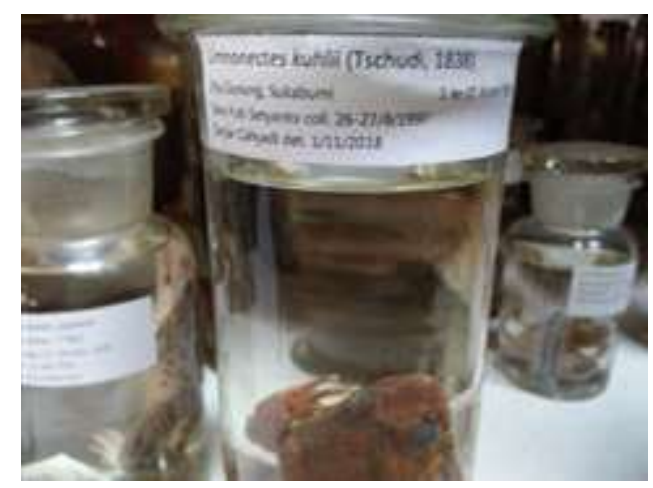

Gambar 3. Contoh Spesimen Basah Limnonectes Kuhlii Pada Botol Kaca Sumber: Museum Zoologi SITH ITB (2020)

Museum Zoologi SITH ITB pun memiliki spesimen basah dalam botol yang tidak untuk dipajang, khusus untuk penelitian dan persediaan koleksi. Kurator menyimpan beberapa koleksi basah yang disimpan dalam lemari khusus untuk bahan penelitian dan persediaan koleksi museum. Kadangkala, ada beberapa koleksi museum basah yang rusak atau kering hingga rapuh sehingga tidak bisa dipajang. Maka, kurator mengambil koleksi dari lemari khusus untuk dipajang di museum. Narasumber menceritakan bahwa kurator pada tahun 1990-an menggunakan cairan formalin untuk mengawetkan koleksi basah Cairan formalin sendiri berfungsi untuk fiksasi atau, "Perasaan terikat atau terpusat pada sesuatu secara berlebihan" (Pusat Bahasa, 2019). Arti dari kata perasaan terikat atau terpusat ialah cairan formalin dapat memudahkan membentuk koleksi yang akan diawetkan.

Selain koleksi basah di atas, kurator pun menyimpan koleksi kering. Satwa yang diawetkan secara kering diambil dari tulang (artikulasi rangka) dan kulit (opsetan). Kurator menyimpan spesimen yang diawetkan secara kering berupa artikulasi tulang dan kulit pada lemari tertutup dan pajangan terbuka. Pertama, spesimen kering awetan artikulasi rangka 
dan kulit pada lemari tertutup memiliki desain pintu lemari yang dapat digeser, menggunakan kaca di bagian depan, kanan, dan kirinya. Kurator dapat membuka lemari dengan cara digeser untuk mengambil spesimen, dan pengunjung pun dapat melihat secara leluasa koleksi kering artikulasi rangka dan kulit di dalamnya. Lemari ini ternyata memudahkan keluar masuk spesimen, tidak menghalangi saat pengamatam, dan melindungi dari jamur. Tentunya, ukuran ruang lemari telah disesuaikan dengan ukuran spesimen kering yang akan dimasukkan, misalnya tinggi badan spesimen.

Kedua, lemari tertutup pada penyimpanan spesimen kering artikulasi: rangka dan kulit memiliki desain dikelilingi kaca bagian depan, kanan, kiri, dan atas lemari. Lemari ini tidak begitu besar sehingga hanya menyimpan kepala artikulasi rangka dari beberapa spesimen dan spesimen yang ukurannya kecil. Ketiga, lemari pameran pada penyimpanan spesimen kering opsetan (awetan) memiliki desain lemari pajangan tertutup kaca secara penuh. Lemari pameran hanya diperuntukkan bagi spesimen kering opsetan, misalnya harimau. Bagian depan, belakang, kanan, kiri, dan atas menggunakan kaca. Kurator memilih lemari pajangan untuk melindungi spesimen kering dari debu, jamur, dan hama lainnya. Selain itu, menghindari reaksi aktif pengunjung seperti memegang atau menaiki spesimen ini. Lemari pajangan membantu pengunjung dalam mengamati spesimen kering yang dipajangkan, misalnya pengunjung dari sekolah dalam mengamati warna bulu dan anggota tubuh spesimen ini.

Keempat, lemari pameran pada penyimpanan spesimen kering opsetan memiliki desain lemari terbuka. Spesimen dalam lemari terbuka di antaranya spesimen mamalia berbentuk opsetan dan burung berupa artikulasi rangka. Spesimen mamalia (harimau) dan burung disimpan di ruang pajang tanpa tertutup kaca, hanya beralas kayu dan ada yang menggunakan penyangga tulang agar membentuk kerangka.

\section{SIMPULAN}

Museum Zoologi SITH ITB merupakan museum tingkat universitas di Indonesia yang memiliki koleksi spesimen awetan basah dan awetan kering. Penelitian ini berfokus pada kegiatan preservasi preventif yang dimulai dari identifikasi koleksi dan penyimpanan koleksi. Museum Zoologi SITH ITB melakukan pengawetan spesimen agar hewan yang hampir punah atau langka masih dapat dilihat, diamati, dan dipelajari untuk pendidikan dan penelitian. Koleksi Museum Zoologi SITH ITB terdiri dari spesimen invertebrata, ikan, amfibi, reptil, burung, dan mamalia. Spesimen invertebrata menjadi spesimen terbanyak di museum yang diawetkan secara basah dan kering. Spesimen ikan yang diawetkan sebagian 
basah direndam dengan cairan alkohol dan formalin sedangkan awetan kering berupa rangka kepala spesimen.

Spesimen amfibi sebagian besar diawetkan secara basah karena digunakan untuk proses penelitian dan pengajaran. Spesimen reptil sebagian besar diawetkan berupa artikulasi rangka dan opsetan. Adapun spesimen burung diawetkan secara kering yang direndam alcohol terlebih dahulu. Spesimen burung di Museum Zoologi SITH ITB memiliki beragam jenis burung dan sebagian besar burung yang sudah langka atau punah. Spesimen mamalia diawetkan secara kering berupa artikulasi rangka dan opsetan.

Adapun Penyimpanan koleksi Museum Zoologi SITH ITB dilakukan melalui proses analisis koleksi, pengawetan, pelabelan, dan penyimpanan. Pertama, kurator dalam melakukan proses analisis koleksi mengamati hewan yang akan dimatikan untuk dijadikan spesimen dan membuat surat perijinan kepada lembaga berwenang. Kedua, kuratos dalam melakukan pengawetan melakukan pengawetan koleksi spesimen basah dan kering disesuaikan spesimennya sendiri. Ketiga, kurator dalam kegiatan pelabelan melabeli koleksi spesimen basah dan kering sesuai penempatan wadah. Data label terdiri dari nama jenis, suku atau nama latin koleksi, nama kolektor dan tanggal pengambilan, nama identifikator dan tanggal identifikasi, lokasi pengambilan koleksi, jumlah eksemplar, dan ukuran. Terakhir, kurator dalam kegiatan penyimpanan menyimpan koleksi awetan basah dan kering secara berbeda. Koleksi awetan basah disimpan ke dalam botol bertutup, botol dengan permukaan mulutnya yang lebar, dan penggantian cairan formalin ke alkohol. Standar penyimpanan koleksi basah ialah koleksi disimpan dalam botol kaca menggunakan penutup botol bahan kaca. Adapun proses pengawetan bahwa satwa yang diawetkan secara kering diambil dari tulang (artikulasi rangka) dan kulit (opsetan). Kurator menyimpan spesimen yang diawetkan secara kering berupa artikulasi tulang dan kulit pada lemari tertutup dan pajangan terbuka. Penelitian mengenai identifikasi koleksi dan penyimpanan koleksi di Museum Zoologi SITH ITB dapat membantu kurator dalam mengenalkan awetan spesimen kepada pengunjung. Maka, rencana penelitian selanjutnya dapat dilihat dari efektivitas kegiatan preservasi preventif dari sisi pengunjung.

\section{Kontribusi Pada Keilmuan}

Penelitian ini merupakan kajian dalam bidang preservasi dan konservasi yang mengkaji tentang preservasi kuratif. Penelitian ini juga berkaitan dengan bidang permuseuman dan pengelolaan informasi secara umum. Hasil penelitian ini dapat menjadi dasar untuk penelitian selanjutnya atau penelitian bidang sejenis mengenai bagaimana museum terutama museum zoologi dalam melakukan preservasi. Penelitian ini juga dapat menjadi sumber inspirasi bagi penelitian bidang lain yang berhubungan dengan preservasi dan konservasi koleksi pada museum zoologi.

Identifikasi dan penyimpanan koleksi Museum Zoologi Sekolah Ilmu dan Teknologi Hayati (SITH) Institut Teknologi Bandung Jatinangor

(Jaenal Ihsan Kaenuwihanulah, Ninis Agustini Damayani, Rully Khairul Anwar) 


\section{Pernyataan Minat Kajian}

Peneliti bernama Jainal Ihsan Kaenuwihanulah memiliki minat kajian dalam bidang preservasi dan konservasi. Peneliti bernama Ninis Agustini Damayani pun memiliki minat kajian dalam bidang preservasi media dan informasi. Peneliti bernama Rully Khairul Anwar memiliki minat kajian pada bidang komunikasi organisasi.

\section{Kontribusi Peneliti}

Peneliti Jainal Ihsan Kaenuwihanulah melakukan wawancara, observasi, dan pengumpulan data yang kemudian dianalisis. Peneliti Ninis Agustini Damayani dan Rully Khairul Anwar memberikan arahan, masukan, dan koreksi terhadap penelitian yang dilakukan.

\section{DAFTAR PUSTAKA}

Badan Pengembangan dan Pembinaan Bahasa (Pusat Bahasa). (2019). Kamus besar bahasa indonesia (KBBI). Retrieved from https://kbbi.web.id/

Cahyadi, G., Rasyidi, R., \& Permadi, D. (2019). Lighthouses for biodiversity: prospects and challenges for zoological university museum in Indonesia. In Achmadi, A. S., Anita, S., Dwijayanti, E., Budi, A. S., Murniati, D. C., Nurinsiyah, A. S., Qodri, A., Encilia (Eds.), International Symposium on Indonesian Fauna (ISIF) (pp. 1-6). EDP Sciences. Retrieved from https://www.bioconferences.org/articles/bioconf/pdf/2020/03/bioconf_isif2019_00003.pdf

Cahyadi, G. (2020a). Amfibi. Museum Zoologi SITH ITB. Retrieved from http://museumzoologi.sith.itb.ac.id/?page_id=165

Cahyadi, G. (2020b). Burung. Museum Zoologi SITH ITB. Retrieved from http://museumzoologi.sith.itb.ac.id/?page_id=171

Cahyadi, G. (2020c). Ikan. Museum Zoologi SITH ITB. Retrieved from http://museumzoologi.sith.itb.ac.id/?page_id=181

Cahyadi, G. (2020d). Invertebrata. Museum Zoologi SITH ITB. Retrieved from http://museum-zoologi.sith.itb.ac.id/?page_id=184

Cahyadi, G. (2020e). Koleksi museum zoologi SITH ITB. Museum Zoologi SITH ITB. Retrieved from http://museum-zoologi.sith.itb.ac.id/?page_id=61

Cahyadi, G. (2020f). Mamalia. Museum Zoologi SITH ITB. Retrieved from http://museumzoologi.sith.itb.ac.id/?page_id $=178$

Cahyadi, G. (2020g). Reptil. Museum Zoologi SITH ITB. Retrieved from http://museumzoologi.sith.itb.ac.id/?page_id=176

Denzin, N. K., \& Lincoln, Y. S. (2009). Handbook of qualitative research. Yogyakarta: Pustaka Pelajar.

Fitrianti, N. N. (2019). Preservasi naskah kuno di museum prabu geusan ulun sumedang (Skripsi).

https://repository.unpad.ac.id/frontdoor/index/index/year/2020/docId/34725

Hartman, T. (2018). National LiFluid preservation of zoological specimens. In Yong W. (Ed.), Biobanking: methods and protocols, methods in molecular biology (vol. 1897). 
New York: Humana Press. Retrieved from https://doi.org/10.1007/978-1-4939-89355_14

Harvey, R., \& Mahard, M. R. (2014). The preservation management handbook: A 21st century guide for libraries, archives, and museums. New York: Rowman \& Little field. Retrieved from https://books.google.co.id/books?id=1shZAwAAQBAJ\&pg=PA62\&dq=preventive+pres ervation\&hl=id\&sa=X\&ved=0ahUKEwiInZLF6evpAhVh6XMBHYqTB0cQ6AEIKDAA \# $\mathrm{v}=$ onepage\& $\mathrm{q}=$ preventive preservation $\& \mathrm{f}=$ false

Moleong, L. J. (2011). Metodologi penelitian kualitatif (29th ed.). Bandung: Remaja Rosdakarya.

Museum Zoologi SITH ITB. (2020a). Dokumentasi Museum Zoologi SITH ITB yang dibutuhkan (Google Drive). $\quad$ Retrieved from https://drive.google.com/drive/folders/1w5PmyBRsghGKgcLS1lPknQ2mN7Ue18Xu?us $\mathrm{p}=$ sharing

Museum Zoologi SITH ITB. (2020b). Kunjungan Museum zoologi SITH ITB. Retrieved from http://museum-zoologi.sith.itb.ac.id/?page_id=161

Museum Zoologi SITH ITB. (2020c). Museum zoologi SITH ITB. Retrieved from http://museum-zoologi.sith.itb.ac.id/?page_id=7

Pratiwi, R. (2006). Biota laut: II. Bagaimana mengkoleksi dan merawat biota laut. Oseana, 31(2), 1-9. Retrieved from http://oseanografi.lipi.go.id/dokumen/oseana_xxxi(2)1-9.pdf

Undang-Undang Republik Indonesia Nomor 5 Tahun 1990 tentang Konservasi Sumber Daya Alam Hayati dan Ekosistemnya, Pub. L. No. 5 (1990). Retrieved from https://www.hukumonline.com/pusatdata/detail/371/node/22/uu-no-5-tahun-1990konservasi-sumber-daya-alam-hayati-dan-ekosistemnya\#

Rakhmat, J. (2012). Metode penelitian komunikasi: dilengkapi contoh analisis statistik (19th ed.). Bandung: Remaja Rosdakarya.

Sarwono, J. (2006). Metodologi penelitian kuantitatif dan kualitatif. Yogyakarta: Graha Ilmu.

Sugiyono. (2013). Metode penelitian pendidikan: pendekatan kuantitatif, kualitatif, dan $R \& D$ (17th ed.). Bandung: Alfabeta.

Yin, R. K. (2015). Studi kasus: desain dan metode (14th ed.). Jakarta: Rajagrafindo Persada. 